\title{
Association Between Knowledge of Hypoglycemia and Likelihood of Experiencing Hypoglycemia Among Patients with Insulin-Treated Diabetes Mellitus
}

\author{
Turky $\mathrm{H}$ Almigbal (iD) ${ }^{1-3}$ \\ 'Department of Family and Community \\ Medicine, College of Medicine, King Saud \\ University, Riyadh, Saudi Arabia; ${ }^{2}$ King \\ Saud University Medical City, King Saud \\ University, Riyadh, Saudi Arabia; ${ }^{3}$ Vision \\ College of Medicine, Vision Colleges in \\ Riyadh, Riyadh, Saudi Arabia
}

Purpose: This study aimed to evaluate the association between a patient's knowledge about hypoglycemia and the likelihood of experiencing hypoglycemia.

Participants and Methods: This cross-sectional study used a structured questionnaire to survey a representative sample of 429 adult males with insulin-treated diabetes mellitus (ITDM) in Saudi Arabia.

Results: The main factors associated with increased risk of hypoglycemia included (a) a premixed insulin regimen, (b) a long duration of insulin treatment, (c) the use of oral hypoglycemic agents, and (d) a high hypoglycemia knowledge score. Insulin as a treatment modality directly affects the development of hypoglycemia among ITDM patients. Sweating is the most prevalent clinical manifestation among ITDM patients with hypoglycemia and could be an early indicator of hypoglycemia. Earlier detection of hypoglycemic signs may ultimately improve quality of life in ITDM patients.

Conclusion: This research highlights the importance of healthcare providers educating ITDM patients about hypoglycemia. Furthermore, our results emphasize the urgent need to establish an educational program about hypoglycemia. ITDM patients are encouraged to learn more about hypoglycemia to help prevent future hypoglycemic attacks.

Keywords: diabetes mellitus, insulin, hypoglycemia, hypoglycemia symptoms, patient education

\section{Introduction}

Diabetes mellitus (DM) is one of the most prevalent chronic diseases worldwide. ${ }^{1}$ The global prevalence of DM is increasing and expected to rise from 463 million in 2019 to 578 million cases by 2030. In the Middle East, the prevalence of DM is expected to rise from 54.8 million cases in 2019 to 76.0 million in 2030. In Saudi Arabia, DM represents a major public health problem; 4.27 million cases were documented in 2019 , which is projected to reach 6.05 million by $2030 .^{2-5}$

Individuals diagnosed with DM are at greater risk for mortality and morbidity due to diabetic complications, including macrovascular, microvascular, or acute complications. Common macrovascular complications among diabetics include heart failure, peripheral artery disease, and coronary heart disease. ${ }^{6}$ Microvascular complications include end-stage renal disease (ESRD), neuropathy, and diabetic retinopathy, which is a leading cause of blindness worldwide. ${ }^{7}$ The acute
Correspondence: Turky H Almigbal

Email almogbal@yahoo.com 
complications of DM, which include diabetic ketoacidosis (DKA), hyperglycemic hyperosmolar state (HHS), and hypoglycemia, are largely preventable, yet lead to high morbidity and mortality. Although the global status of diabetes complication rates remains unclear, ${ }^{8}$ mortalities due to DM are estimated to contribute to $11.3 \%$ of deaths globally, with the highest rate recorded in the Middle East and North Africa (16.2\%). ${ }^{9}$

Hypoglycemia is the most common iatrogenic acute metabolic complication among diabetics, ${ }^{10-12}$ and it is defined as serum glucose levels $<70 \mathrm{mg} / \mathrm{dL}(3.9 \mathrm{mmol} / \mathrm{L})$, which is mainly encountered by patients on insulin treatment as a result of its hypoglycemic effects. ${ }^{13}$ Although avoidable, hypoglycemia was the primary cause for the elevated number $(300,000)$ of adult emergency department visits in the United States in 2009. ${ }^{14}$ In Saudi Arabia, the rate of acute complications due to hypoglycemic attacks was found to be high at $68.9 \%$ among patients with DM. ${ }^{15}$ Complications due to hypoglycemia can be serious and life threatening, including such as cardiac arrhythmia, cognitive impairment, and cerebral ischemia. ${ }^{16}$

The incidence of hypoglycemia among patients with $\mathrm{DM}$ is high, ${ }^{17}$ and poor hypoglycemia awareness can render diabetics prone to severe hypoglycemia. ${ }^{18}$ It is important to identify the association between hypoglycemia and related factors, such as the patient's hypoglycemia experience, awareness of glycemic control, and hypoglycemia itself. This information may help minimize or even eliminate the potential harm to patients with DM receiving insulin treatment.

Studies have shown that adequate knowledge about hypoglycemia is needed to recognize, treat, and prevent hypoglycemia, ${ }^{19}$ yet patients with DM have a gap in their knowledge on important aspects of hypoglycemia. ${ }^{20}$ Improved hypoglycemia knowledge in diabetic patients led to a decrease in hypoglycemic episodes. ${ }^{21}$ In Saudi Arabia, research has shown that approximately $50 \%$ of patients with DM have a lack of knowledge about hypoglycemia symptoms; the authors concluded that health education about hypoglycemia symptoms is necessary for these patients. ${ }^{22}$

Our study focuses on the association between diabetic patients' knowledge about hypoglycemia and their likelihood of experiencing a hypoglycemic episode. Furthermore, we studied the association between various sociodemographic and clinical variables and hypoglycemia among patients with insulin-treated diabetes mellitus (ITDM) in Saudi Arabia.

\section{Methods}

\section{Study Design and Settings}

This research project was part of the Diabetes and Driving (DAD) study, which was a cross-sectional study conducted among ITDM participants in which data were collected from two specialized diabetes clinics affiliated with tertiary hospitals in Riyadh, Saudi Arabia. The detailed methodology of the DAD study was previously published and will be briefly described here. ${ }^{23}$

\section{Participant Enrollment}

The participants of the DAD study consisted of adult men (age $>18$ ) with ITDM who were followed up for a minimum of 1 year in the diabetes clinic. ${ }^{23}$ The data were collected by interviewing participants who met the eligibility criteria and who consented to participating after they had completed their clinic consultations; the study's objectives were explained, and written consent was obtained. Four datacollection-experienced medical students collected the data at random 4-h intervals every other day over a seven-month period extending from August 2016 to February 2017. The four students who collected the data were informed of the study's objectives, and the questionnaire was explained to them by the principal investigator; these four students also participated in the pilot study.

\section{Study Instrument}

The interview questionnaire was developed following an extensive literature review and is based on available international guidelines; the process is discussed in detail in the original study. ${ }^{23}$ The questionnaire was initially developed in English and was then translated to Arabic and backtranslated to English by two accredited translators. The final Arabic version was piloted among 20 participants from general medicine clinics. The questionnaire's reliability was tested using the test-retest method, yielding a correlation coefficient $>0.7$ for all items.

\section{Study Sample}

The required calculated sample size was 399 based on the results of the pilot study. Due to a $20 \%$ non-response rate in the pilot study, the final sample size required was 499 participants. $^{23}$

\section{Statistical Analysis}

Descriptive statistics were used to analyze the collected data in the form of frequency values. Multivariable logistic 
regression analyses were performed to identify factors that may increase the risk of hypoglycemia among participants with ITDM. The study results were considered statistically significant when $\mathrm{P}<0.05$. The Kolmogorov-Smirnov test was used to determine the normality of the data. All data were analyzed using SPSS Statistics V22.0 (IBM Corp., Armonk, NY, USA). ${ }^{24,25}$

\section{Ethical Considerations}

The institutional review board at King Saud University Medical City (Saudi Arabia, Riyadh) granted ethical approval of the original study's protocol (Ref. No. 16/ 0227/IRB). This study was conducted in accordance with the Declaration of Helsinki.

\section{Results}

The questionnaire had a response rate of $89.3 \%$; 429 of the 480 initially approached ITDM patients agreed and consented to be interviewed and to participate in the study. More than half of the sample (59.7\%) had ITDM for $\geq 15$ years, and approximately half of the sample $(51.3 \%)$ had used insulin for $\geq 5$ years. Additional sociodemographic variables are listed in Table 1. Knowledge of hypoglycemic symptoms among ITDM patients varied widely (Table 2 ). The most recognized hypoglycemia symptoms were tremor $(90.68 \%)$, hunger $(85.78 \%)$, and sweating (85.31\%). Knowledge of tremor and hunger symptoms did not differ significantly between ITDM patients who did and did not experience hypoglycemia. In contrast, sweating was the most recognized symptom among ITDM patients, and the number of ITDM patients who experienced hypoglycemia who were knowledgeable about sweating $(n=255)$ was approximately twice that of ITDM patients who did not experience hypoglycemia $(\mathrm{n}=111)$. In addition to sweating, ITDM patients who experienced hypoglycemia were more knowledgeable, relative to those who did not experience hypoglycemia, about the symptoms of cognitive impairment $(49.14 \%$ vs $29.71 \%$; $\mathrm{P}<0.001)$, behavioral changes $(43.99 \%$ vs 22.46 ; $\mathrm{P}=0.001)$, psychomotor abnormalities $(35.05 \%$ vs $15.22 \% ; \mathrm{P}<0.001)$, and coma $(34.36 \%$ vs $22.46 \%$; $\mathrm{P}=0.012)$

Experiencing hypoglycemia was associated with various sociodemographic characteristics. Type of DM, insulin regimen, insulin total daily dose, duration of insulin treatment, use of oral hypoglycemics, and hypoglycemia knowledge score all showed a statistically significant
Table I Sociodemographic Data for the Study Sample $(N=429)$

\begin{tabular}{|c|c|c|}
\hline \multicolumn{2}{|c|}{ Participant Sociodemographics } & \multirow{2}{*}{$\begin{array}{l}\mathbf{n}^{\mathbf{a}}(\%) \\
323(75.3) \\
106(24.7)\end{array}$} \\
\hline Age (years) & $\begin{array}{l}\leq 60 \\
>60\end{array}$ & \\
\hline Highest education level & $\begin{array}{l}\text { No school attended } \\
\text { Primary school attended } \\
\text { Secondary=school attended } \\
\text { Tertiary school attended } \\
\text { University or college } \\
\text { Master or PhD }\end{array}$ & $\begin{array}{l}16(3.7) \\
61(14.3) \\
57(13.3) \\
134(31.2) \\
130(30.4) \\
31(7.2)\end{array}$ \\
\hline Location & $\begin{array}{l}\text { Riyadh } \\
\text { Outside Riyadh }\end{array}$ & $\begin{array}{l}409(95.3) \\
20(4.7)\end{array}$ \\
\hline Current occupation & $\begin{array}{l}\text { Unemployed } \\
\text { Private work } \\
\text { Governmental work } \\
\text { Retired }\end{array}$ & $\begin{array}{l}54(12.6) \\
65(15.2) \\
142(33.1) \\
168(39.2)\end{array}$ \\
\hline Monthly income & $\begin{array}{l}<5000 \mathrm{SR}^{\mathrm{b}} \\
5000-10,000 \mathrm{SR} \\
10,001-15,000 \mathrm{SR} \\
>15,000 \mathrm{SR}\end{array}$ & $\begin{array}{l}150(35) \\
135(31.5) \\
87(20.3) \\
57(13.3)\end{array}$ \\
\hline Type of diabetes & $\begin{array}{l}\text { Type } 1 \\
\text { Type } 2\end{array}$ & $\begin{array}{l}112(26.1) \\
317(73.9)\end{array}$ \\
\hline $\begin{array}{l}\text { Duration of diabetes } \\
\text { (years) }\end{array}$ & $\begin{array}{l}\leq 15 \\
>15\end{array}$ & $\begin{array}{l}256(59.7) \\
173(40.3)\end{array}$ \\
\hline Insulin regimen & $\begin{array}{l}\text { Basal only } \\
\text { Pre-mixed insulin } \\
\text { Basal/boluses }\end{array}$ & $\begin{array}{l}93(21.7) \\
189(44.1) \\
147(34.2)\end{array}$ \\
\hline $\begin{array}{l}\text { Total daily dose of } \\
\text { insulin }(U)\end{array}$ & $\begin{array}{l}\leq 62 \\
>62\end{array}$ & $\begin{array}{l}234(54.5) \\
195(45.5)\end{array}$ \\
\hline $\begin{array}{l}\text { Duration of insulin } \\
\text { treatment (years) }\end{array}$ & $\begin{array}{l}\leq 5 \\
>5\end{array}$ & $\begin{array}{l}220(51.3) \\
209(48.7)\end{array}$ \\
\hline $\begin{array}{l}\text { Use of Sulphonylurea or } \\
\text { Glinides }\end{array}$ & $\begin{array}{l}\text { Yes } \\
\text { No }\end{array}$ & $\begin{array}{l}110(25.6) \\
319(74.4)\end{array}$ \\
\hline
\end{tabular}

Notes: ${ }^{a}$ Number; ${ }^{\text {b}}$ Saudi riyal.

unadjusted association with experiencing hypoglycemia ( $\mathrm{P}<0.05)$. Further, $70.45 \%$ of ITDM patients who experienced hypoglycemia had type $2 \mathrm{DM}$, whereas only $29.55 \%$ had type $1 \mathrm{DM}(\mathrm{P}=0.018)$. In addition to DM type, a higher duration of insulin treatment was associated with hypoglycemia, with a mean duration of $8.25 \pm 7.02$ years $(\mathrm{P}<0.001)$. Regarding the insulin treatment regimen, hypoglycemia was more prevalent among participants using premixed insulin compared to other insulin regimens $(46.74 \%)$ of a basal/boluses insulin regimen (35.74\%; $\mathrm{P}=0.002)$. Higher hypoglycemia knowledge scores were associated with experiencing hypoglycemia 
Table 2 Hypoglycemia Symptoms Among Patients Who Did and Did Not Experience Hypoglycemia

\begin{tabular}{|c|c|c|c|c|}
\hline \multirow{2}{*}{ Clinical Manifestation } & Hypoglycemia & No Hypoglycemia & Total & \multirow[t]{2}{*}{$\mathbf{P}$} \\
\hline & $\mathrm{n}^{\mathrm{a}}(\%)$ & $\mathrm{n}^{\mathrm{a}}(\%)$ & $\mathrm{n}^{\mathrm{a}}(\%)$ & \\
\hline \multicolumn{5}{|l|}{ Adrenergic symptoms } \\
\hline Tremor & $268(92.10 \%)$ & $12 \mid(87.68 \%)$ & 389 (90.68\%) & 0.142 \\
\hline Palpitations & $214(73.54 \%)$ & 97 (70.29\%) & $311(72.49 \%)$ & 0.481 \\
\hline Anxiety/arousal & 185 (63.57\%) & $94(68.12 \%)$ & $279(65.03 \%)$ & 0.357 \\
\hline Sweating & $255(87.63 \%)$ & III (80.43\%) & $366(85.31 \%)$ & 0.049 \\
\hline Hunger & $251(86.25 \%)$ & 117 (84.78\%) & $368(85.78 \%)$ & 0.683 \\
\hline Paresthesia & $170(58.42 \%)$ & $73(52.90 \%)$ & $243(56.64 \%)$ & 0.281 \\
\hline \multicolumn{5}{|c|}{ Neuroglycopenic symptoms } \\
\hline Cognitive impairment & 143 (49.14\%) & $4 \mid(29.71 \%)$ & $184(42.89 \%)$ & $<0.001$ \\
\hline Behavioral changes & 128 (43.99\%) & 31 (22.46\%) & $159(37.06 \%)$ & $<0.001$ \\
\hline Psychomotor abnormalities & $102(35.05 \%)$ & $21(15.22 \%)$ & $123(28.67 \%)$ & $<0.001$ \\
\hline Seizure & $26(8.93 \%)$ & II (7.97\%) & $37(8.62 \%)$ & 0.741 \\
\hline Coma & $100(34.36 \%)$ & $31(22.46 \%)$ & $|3|(30.54 \%)$ & 0.012 \\
\hline
\end{tabular}

(mean knowledge score: $6.33 \pm 2.49 ; \mathrm{P}<0.001$ ). No significant association was found between experiencing hypoglycemia and the remaining sociodemographic characteristics, as illustrated in Table 3. Regarding hypoglycemia, a higher knowledge score increased the likelihood of ITDM patients experiencing hypoglycemia by $15 \%$ relative to other patients [OR $=1.15(1.049,1.26) ; \mathrm{P}=0.003$ ]. A longer duration of insulin treatment (in years) also increases the chance of experiencing hypoglycemia by $6 \%[\mathrm{OR}=1.06(1.009,1.11) ; \mathrm{P}=0.021]$. ITDM patients who receive a higher total daily insulin dose are at $1 \%$ higher risk of experiencing hypoglycemia $[\mathrm{OR}=1.01$ (1.003, 1.02); $\mathrm{P}=0.004$; Table 4].

Regarding low hypoglycemia knowledge scores $(\leq 6)$, ITDM patients who did not experience hypoglycemia were $52 \%$ more likely to have a lower knowledge score than those who experienced hypoglycemia (Table 5).

\section{Discussion}

The current study sought to evaluate the association between ITDM patients' knowledge of hypoglycemia and their likelihood of experiencing a hypoglycemic episode. Furthermore, this study identified sociodemographic characteristics that may be risk factors for hypoglycemia among adult ITDM patients within Saudi Arabia. Further research is warranted on the correlation between experiencing hypoglycemia in ITDM patients and additional sociodemographic factors, such as type of diabetes, duration of diabetes, duration of insulin treatment, and total daily insulin dose. Hypoglycemic symptoms fall into two main categories: adrenergic symptoms are caused by rapid changes in glucose levels, while neuroglycopenic symptoms are caused by low levels of central nervous system glucose. ${ }^{26}$ In their study, $87.63 \%$ of the ITDM patients who experienced hypoglycemia were found to report sweating as the most significant clinical symptom associated with hypoglycemic attack. In other studies, ${ }^{27}$ sweating was the most commonly reported symptom among ITDM patients. In addition, nearly half of the sample's constituents who experienced hypoglycemia complained of cognitive impairment and behavioral changes at rates of $49 \%$ and approximately $44 \%$, respectively. The high rate of sweating as a clinical symptom among ITDM patients who developed hypoglycemia suggests that sweating can be used as a warning sign to prevent the development of a severe hypoglycemic attack. Such an observation was reported in a scientific report, which found that sweating during hypoglycemia may be a noninvasive warning sign. ${ }^{18}$

We also found evidence for a direct relationship between experiencing hypoglycemia and multiple sociodemographic characteristics among ITDM patients including the DM type, duration of insulin treatment in years, total daily insulin doses, and a good hypoglycemia knowledge score. Based on the type of DM, patients with type 2 DM were twice as likely to experience hypoglycemia than type $1 \mathrm{DM}$ patients. The duration of insulin treatment affects the likelihood of developing hypoglycemia; ITDM patients with more years of insulin treatment have a $6 \%$ higher chance of developing hypoglycemia 
Table 3 Sociodemographic Characteristics Related to Experiencing Hypoglycemia in ITDM Patients

\begin{tabular}{|c|c|c|c|c|}
\hline Sociodemographics & Hypoglycemia & No Hypoglycemia & Total & $P$ \\
\hline Age (Years) & $48.59 \pm 16.05$ & $51.54 \pm 13.06$ & $49.54 \pm 15.20$ & 0.060 \\
\hline Education & & & & 0.766 \\
\hline No school & 9 (3.09\%) & 7 (5.07\%) & $16(3.73 \%)$ & \\
\hline Primary school & 42 (I4.43\%) & 19 (13.77\%) & 61 (14.22\%) & \\
\hline Secondary school & 41 (14.09\%) & $16(11.59 \%)$ & 57 (I3.29\%) & \\
\hline Tertiary school & 87 (29.90\%) & 47 (34.06\%) & 134 (31.24\%) & \\
\hline University or college & 89 (30.58\%) & 41 (29.7I\%) & I 30 (30.30\%) & \\
\hline Master or $\mathrm{PhD}$ & 23 (7.90\%) & $8(5.80 \%)$ & 31 (7.23\%) & \\
\hline Current Occupation & & & & $0.77 I$ \\
\hline Unemployed & 40 (I3.75\%) & $14(10.14 \%)$ & 54 (I2.59\%) & \\
\hline Governmental work & 95 (32.65\%) & 47 (34.06\%) & 142 (33.10\%) & \\
\hline Private work & $44(15.12 \%)$ & 21 (15.22\%) & 65 (15.15\%) & \\
\hline Retired & II 2 (38.49\%) & 56 (40.58\%) & 168 (39.16\%) & \\
\hline Monthly Income & & & & 0.722 \\
\hline$<5000 \mathrm{SR}$ & $103(35.40 \%)$ & 47 (34.06\%) & 150 (34.97\%) & \\
\hline $5000-10,000$ SR & 95 (32.65\%) & 40 (28.99\%) & | 35 (31.47\%) & \\
\hline $10,00 I-15,000$ SR & 55 (I8.90\%) & $32(23.19 \%)$ & 87 (20.28\%) & \\
\hline$>15,000 S R$ & 38 (I3.06\%) & 19 (13.77\%) & 57 (13.29\%) & \\
\hline Smoking Status & & & & 0.277 \\
\hline Never smoked & 163 (56.01\%) & 81 (58.70\%) & 244 (56.88\%) & \\
\hline Current smoker & $63(21.65 \%)$ & 35 (25.36\%) & 98 (22.84\%) & \\
\hline Former smoker & 65 (22.34\%) & 22 (I5.94\%) & 87 (20.28\%) & \\
\hline Marital status & & & & 0.171 \\
\hline Single & 49 (16.84\%) & 13 (9.42\%) & $62(14.45 \%)$ & \\
\hline Married & 235 (80.76\%) & 123 (89.13\%) & 358 (83.45\%) & \\
\hline Divorced & 5 (1.72\%) & I (0.72\%) & $6(1.40 \%)$ & \\
\hline Widowed & $2(0.69 \%)$ & I (0.72\%) & $3(0.70 \%)$ & \\
\hline Location by City & & & & 0.482 \\
\hline Riyadh & $276(94.85 \%)$ & $133(96.38 \%)$ & 409 (95.34\%) & \\
\hline Outside Riyadh & $15(5.15 \%)$ & $5(3.62 \%)$ & $20(4.66 \%)$ & \\
\hline Type of diabetes & & & & 0.018 \\
\hline Type I & $86(29.55 \%)$ & $26(18.84 \%)$ & 112 (26.II\%) & \\
\hline Type 2 & 205 (70.45\%) & II 2 (8I.16\%) & 317 (73.89\%) & \\
\hline Duration of diabetes (Years) & $14.78 \pm 8.73$ & $13.46 \pm 7.75$ & $14.36 \pm 8.44$ & 0.131 \\
\hline Regimen of insulin & & & & 0.002 \\
\hline Basal only & $48(16.49 \%)$ & $45(32.61 \%)$ & $93(21.68 \%)$ & \\
\hline Pre-mixed Insulin & I 36 (46.74\%) & $53(38.41 \%)$ & I 89 (44.06\%) & \\
\hline Basal/Boluses & $104(35.74 \%)$ & $40(28.99 \%)$ & I 44 (33.57\%) & \\
\hline Insulin pump & $3(1.03 \%)$ & $0(0.00 \%)$ & $3(0.70 \%)$ & \\
\hline Use of oral hypoglycemic & $62(21.31 \%)$ & $48(34.78 \%)$ & 110 (25.64\%) & 0.003 \\
\hline Duration of insulin treatment (Years) & $8.25 \pm 7.02$ & $5.47 \pm 5.42$ & $7.35 \pm 6.67$ & $<0.001$ \\
\hline Insulin total daily dose & $66.41 \pm 32.40$ & $52.47 \pm 31.81$ & $61.93 \pm 32.83$ & $<0.001$ \\
\hline Glucose checking & & & & 0.105 \\
\hline Once or more than once daily & $94(32.30 \%)$ & $34(24.64 \%)$ & I 28 (29.84\%) & \\
\hline Not daily & $197(67.70 \%)$ & $104(75.36 \%)$ & 301 (70.16\%) & \\
\hline Knowledge score & $6.33 \pm 2.49$ & $5.42 \pm 2.36$ & $6.04 \pm 2.49$ & $<0.001$ \\
\hline
\end{tabular}


Table 4 Variables Predicting Hypoglycemia Experience Among ITDM Patients

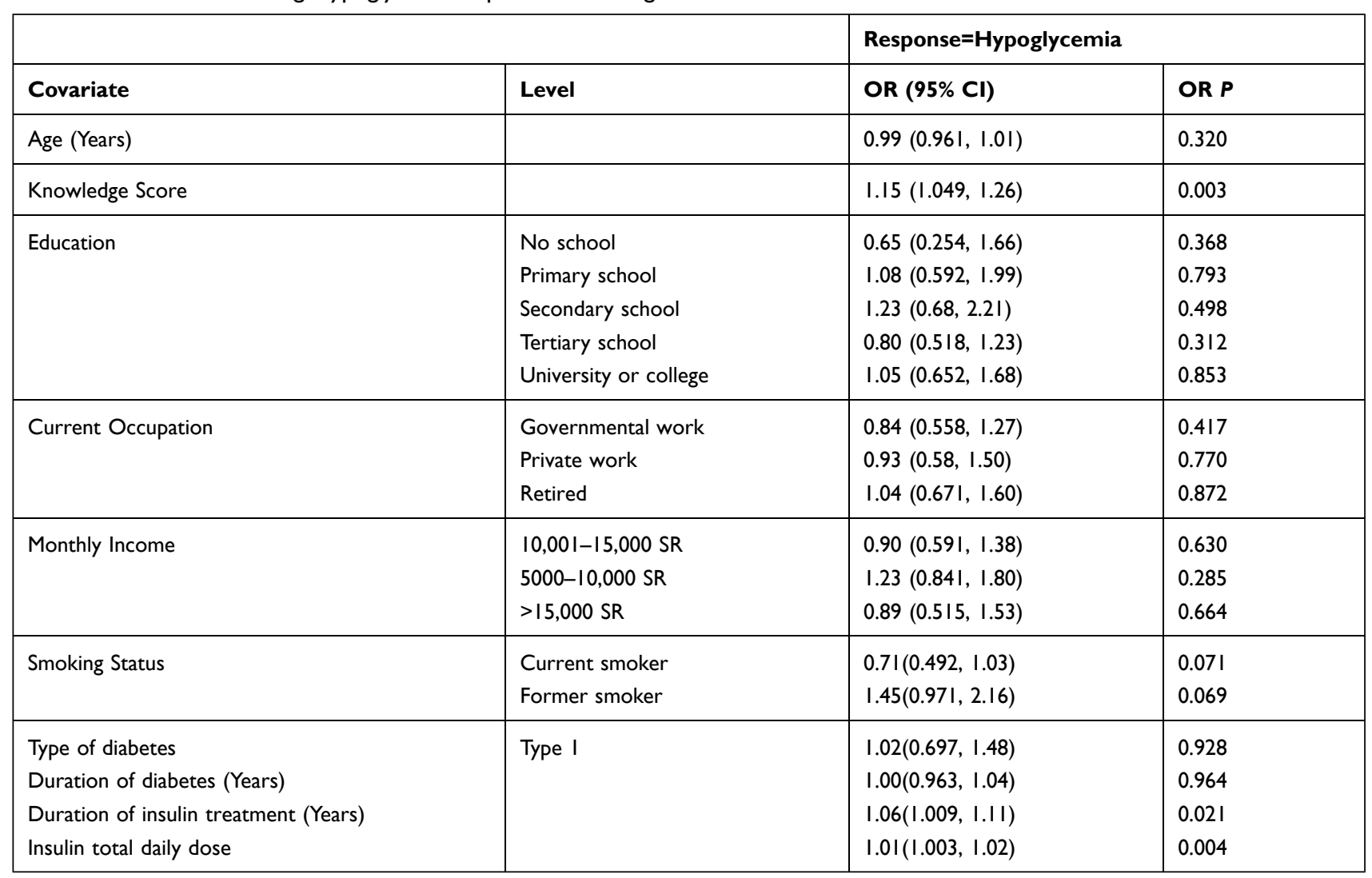

Table 5 Variables Predicting Poor Knowledge Score ( $\leq 6)$ About Hypoglycemia Among ITDM Patients

\begin{tabular}{|c|c|c|c|}
\hline \multirow[b]{2}{*}{ Covariate } & \multirow[b]{2}{*}{ Level } & \multicolumn{2}{|c|}{ Response $=$ Knowledge Score $\leq 6$} \\
\hline & & OR $(95 \% \mathrm{Cl})$ & OR P \\
\hline Age (Years) & & I.0I $(0.985,1.03)$ & 0.469 \\
\hline Education & $\begin{array}{l}\text { No school } \\
\text { Primary school } \\
\text { Secondary school } \\
\text { Tertiary school } \\
\text { University or college }\end{array}$ & $\begin{array}{l}0.72(0.273, I .90) \\
0.81(0.462, I .43) \\
0.97(0.567, I .67) \\
I .05(0.698, I .59) \\
I .57(0.997,2.47)\end{array}$ & $\begin{array}{l}0.506 \\
0.476 \\
0.916 \\
0.807 \\
0.052\end{array}$ \\
\hline Current Occupation & $\begin{array}{l}\text { Governmental work } \\
\text { Private work } \\
\text { Retired }\end{array}$ & $\begin{array}{l}0.79(0.54 \mathrm{I}, \mathrm{I} . \mathrm{I} 5) \\
0.84(0.54, \mathrm{I} .3 \mathrm{I}) \\
\mathrm{I} .0 \mathrm{I}(0.666, \mathrm{I} .53)\end{array}$ & $\begin{array}{l}0.216 \\
0.443 \\
0.958\end{array}$ \\
\hline Monthly Income & $\begin{array}{l}10,00 \mid-15,000 S R \\
5000-10,000 S R \\
>15,000 S R\end{array}$ & $\begin{array}{l}0.86(0.576, \mathrm{I} .30) \\
\mathrm{I} . \mathrm{II}(0.782, \mathrm{I} .58) \\
0.70(0.424, \mathrm{I} .16)\end{array}$ & $\begin{array}{l}0.482 \\
0.556 \\
0.168\end{array}$ \\
\hline Smoking Status & $\begin{array}{l}\text { Current smoker } \\
\text { Former smoker }\end{array}$ & $\begin{array}{l}0.77(0.547,1.09) \\
0.96(0.666,1.37)\end{array}$ & $\begin{array}{l}0.139 \\
0.807\end{array}$ \\
\hline Experienced hypoglycemia & No & $1.52(1.202,1.92)$ & $<0.001$ \\
\hline $\begin{array}{l}\text { Type of diabetes } \\
\text { Duration of diabetes (Years) } \\
\text { Duration of insulin treatment (Years) } \\
\text { Insulin total daily dose }\end{array}$ & Type I & $\begin{array}{l}0.78(0.554,1.09) \\
1.00(0.961,1.03) \\
1.01(0.962,1.05) \\
1.00(0.989,1.00)\end{array}$ & $\begin{array}{l}0.141 \\
0.856 \\
0.803 \\
0.178\end{array}$ \\
\hline
\end{tabular}


compared to those with fewer years of insulin use. A similar finding was described in a study that found a positive correlation between the NPH insulin among ITDM patients and nocturnal hypoglycemia. ${ }^{28}$ Despite the low magnitude of the odds ratio between the duration of insulin treatment and the development of hypoglycemia, there is nevertheless a positive and statistically significant relationship. While the total insulin daily dose showed an association with hypoglycemia, it was to a lesser degree, as the ITDM patients receiving higher doses of daily insulin were only $1 \%$ more prone to hypoglycemia. ITDM patients were expected to develop more comprehensive knowledge about hypoglycemia, diabetes control, and self-care with a longer course of treatment; however, the converse was found to be true. Consequently, a low hypoglycemia knowledge score was directly affected by ITDM patients' hypoglycemia experience. Therefore, our main finding was that the knowledge score of ITDM patients was $15 \%$ higher among patients who experienced hypoglycemia than among those who did not. A low hypoglycemia knowledge score $(\leq 6)$ was more common among IDTM patients who did not experience hypoglycemia than among those who did. This suggests that experiencing hypoglycemia as an outcome motivated ITDM patients to educate themselves about hypoglycemia, thereafter presumably engaging in better self-care to avoid future hyperglycemic episodes. This finding also highlights the importance of knowledge in reducing the risks associated with diabetes among ITDM patients. Similar observations have been reported wherein hypoglycemia knowledge was found to be critical to diabetic patients' self-care. ${ }^{19}$ Such observations require further research that specifically defines both the factors affecting poor knowledge of hypoglycemic symptoms among ITDM patients and how diabetic knowledge - both of broad and specific knowledge about hypoglycemia outcomes - affects the develops of adverse effects.

Several conclusions can be drawn from this study that can help inform clinical practice. First, the majority of the participants with ITDM did experience sweating during hypoglycemic episodes; this can be used to develop an early warning sign system for the patient that may help lower the risk of developing hypoglycemia. Additionally, healthcare providers should encourage ITDM patients to participate in regular follow-up to monitor blood sugar levels, given that differences in insulin treatment parameters can yield differential effects on the development of hypoglycemia. Second, most of the participants with
ITDM who did not experience hypoglycemia had a low hypoglycemia knowledge score. Educating these patients about diabetes is an important intervention for reducing hypoglycemia events among them. ${ }^{29}$ In addition, knowledge about hypoglycemia may produce more normal physiologic insulin profiles, with an associated lower risk of hypoglycemia. ${ }^{30}$

This study had some limitations. Due to the study's design, data were collected via questionnaire; therefore, the quality of the data collected may have been affected by a recall bias. In addition, because the study targeted individuals with ITDM, the results may not be generalizable to evaluating the risk of experiencing hypoglycemia among other DM patients who are not receiving insulin treatments. Nevertheless, the strengths of our study included its large sample size and the novelty of the researched topic in Saudi Arabia.

\section{Conclusions}

This study identifies a connection between hypoglycemia and a multitude of variables in ITDM patients. The major issue exposing ITDM patients at risk of hypoglycemia was a lack of understanding about hypoglycemia. Although the knowledge score was greater in hypoglycemic individuals, it was comparatively low in people who did not develop hypoglycemia. Type 2 diabetics had a greater rate of hypoglycemia. The insulin treatment itself appears to directly affect the development of hypoglycemia in ITDM patients, with a number of factors playing contributing roles, such as the duration of treatment, the type of insulin, and the total number of total daily units. Finally, sweating was the most common clinical manifestation among hypoglycemic individuals, which could improve ITDM patients' quality of life if employed as an early warning indication of hypoglycemia.

\section{Abbreviations}

ITDM, type 1 diabetes mellitus; ESRD, end-stage renal disease; DKA, diabetic ketoacidosis; HHS, hyperglycemic hyperosmolar state; DAD, diabetes and driving.

\section{Data Sharing Statement}

The data analyzed during the current study are available from the corresponding author upon reasonable request.

\section{Ethics Statement}

This study was approved by the Institutional Review Board (IRB) of the College of Medicine at King Saud 
University (Ref. No. 16/0227/IRB). Additionally, the study was conducted in accordance with the Declaration of Helsinki. All participants provided written informed consent.

\section{Funding}

This project was supported by the College of Medicine Research Centre, Deanship of Scientific Research, King Saud University, Riyadh, Saudi Arabia.

\section{Disclosure}

The author reports no conflicts of interest for this work.

\section{References}

1. Khan IA, Movva S, Shaik NA, et al. Investigation of calpain 10 (rs2975760) gene polymorphism in Asian Indians with gestational diabetes mellitus. Meta Gene. 2014;2:299-306. doi:10.1016/j. mgene.2014.03.001

2. Alqurashi KA, Aljabri KS, Bokhari SA. Prevalence of diabetes mellitus in a Saudi community. Ann Saudi Med. 2011;31(1):19-23. doi:10.4103/0256-4947.75773

3. Federation ID. International diabetes federation: IDF diabetes atlas. Brussels, Belgium; 2019. Available from: https://www.diabetesatlas. org. Accessed August 25, 2021.

4. Saeedi P, Petersohn I, Salpea P, et al. Global and regional diabetes prevalence estimates for 2019 and projections for 2030 and 2045: results from the international diabetes federation diabetes atlas. Diabetes Res Clin Pract. 2019;157:107843. doi:10.1016/j. diabres.2019.107843

5. Alharbi KK, Abudawood M, Khan IA. Amino-acid amendment of arginine-325-tryptophan in rs13266634 genetic polymorphism studies of the SLC30A8 gene with type 2 diabetes-mellitus patients featuring a positive family history in the Saudi population. $J$ King Saud Univ Sci. 2021;33(1):101258. doi:10.1016/j.jksus.2020.101258

6. Glovaci D, Fan W, Wong ND. Epidemiology of diabetes mellitus and cardiovascular disease. Curr Cardiol Rep. 2019;21(4):1-8. doi:10.1007/s11886-019-1107-y

7. Liew G, Wong VW, Ho IV. Mini review: changes in the incidence of and progression to proliferative and sight-threatening diabetic retinopathy over the last 30 years. Ophthalmic Epidemiol. 2017;24 (2):73-80. doi:10.1080/09286586.2016.1259638

8. Harding JL, Pavkov ME, Magliano DJ, Shaw JE, Gregg EW. Global trends in diabetes complications: a review of current evidence. Diabetologia. 2019;62(1):3-16. doi:10.1007/s00125-018-4711-2

9. Saeedi P, Salpea P, Karuranga S, et al. Mortality attributable to diabetes in 20-79 years old adults, 2019 estimates: results from the international diabetes federation diabetes atlas. Diabetes Res Clin Pract. 2020;162:108086. doi:10.1016/j.diabres.2020.108086

10. Hanumanthaiah RG, Krishnappa PPB, Prasad D, Farahat S, Ranganath T. Acute metabolic complications of diabetes mellitus in a tertiary care center. Int $J$ Adv Med. 2017;4(4):985. doi:10.18203/ 2349-3933.ijam20173071

11. Cryer PE. Hypoglycemia in type 1 diabetes mellitus. Endocrinol Metab Clin North Am. 2010;39(3):641-654. doi:10.1016/j. ecl.2010.05.003

12. Zimmerman C. Iatrogenic Complications of Diabetes Mellitus: An Examination of Hospital-Acquired Diabetic Ketoacidosis and Severe Outpatient Hypoglycemia[Thesis]. Yale Medicine Thesis Digital Library; 2019:3546. Available from: https://elischolar.library.yale. edu/cgi/viewcontent.cgi?article=3546\&context=ymtdl.
13. Cryer PE. Hypoglycemia: still the limiting factor in the glycemic management of diabetes. Endocr Pract. 2008;14(6):750-756. doi:10.4158/EP.14.6.750

14. Freeland B. Hypoglycemia in diabetes mellitus. Home Healthc Now. 2017;35(8):414-419. doi:10.1097/NHH.0000000000000584

15. Al-Agha AE, Alafif M, Abd-Elhameed IA. Glycemic control, complications, and associated autoimmune diseases in children and adolescents with type 1 diabetes in Jeddah, Saudi Arabia. Saudi Med J. 2015;36(1):26. doi:10.15537/smj.2015.1.9829

16. Ahmed B, Khan MN. Hypoglycemia: its effect on patients with diabetes. World Fam Med. 2019;17(9):18-23. doi:10.5742/ MEWFM.2019.93675

17. AlKhaldi YM, AlKhaldi AY, AlQahtani AS, Al-Shahrani BS, Meshawi EA, Albishri BM. Incidence of hypoglycemia and its risk factors among diabetics during Ramadan in Abha city, Aseer Region, KSA. J Fam Med Prim Care. 2019;8(9):2793. doi:10.4103/jfmpc. jfmpc_250_19

18. Elvebakk O, Tronstad C, Birkeland KI, et al. Evaluation of hypoglycaemia with non-invasive sensors in people with type 1 diabetes and impaired awareness of hypoglycaemia. Sci Rep. 2018;8(1):1-11. doi:10.1038/s41598-018-33189-1

19. Drass JA, Feldman RH. Knowledge about hypoglycemia in young women with type I diabetes and their supportive others. Diabetes Educ. 1996;22(1):34-38. doi:10.1177/014572179602200105

20. Shriraam V, Mahadevan S, Anitharani M, et al. Knowledge of hypoglycemia and its associated factors among type 2 diabetes mellitus patients in a Tertiary Care Hospital in South India. Indian J Endocrinol Metab. 2015;19(3):378. doi:10.4103/2230-8210.152779

21. Bhutani G, Kalra S, Lamba S, Verma PK, Saini R, Grewal M. Effect of diabetic education on the knowledge, attitude and practices of diabetic patients towards prevention of hypoglycemia. Indian J Endocrinol Metab. 2015;19(3):383. doi:10.4103/2230-8210.152781

22. Elzubier AG. Knowledge of hypoglycemia by primary health care centers registered diabetic patients. Saudi Med J. 2001;22 (3):219-222.

23. Almigbal TH, Alfaifi AA, Aleid MA, et al. Safe driving practices and factors associated with motor-vehicle collisions among people with insulin-treated diabetes mellitus: results from the Diabetes and Driving (DAD) Study. J Safety Res. 2018;65:83-88. doi:10.1016/j. jsr.2018.03.003

24. Corp I. IBM SPSS Statistics for Windows, Version 22.0. Armonk, NY: IBM Corp; 2013.

25. Khan IA, Jahan P, Hasan Q, Rao P. Genetic confirmation of T2DM meta-analysis variants studied in gestational diabetes mellitus in an Indian population. Diabetes Metab Syndr. 2019;13(1):688-694. doi:10.1016/j.dsx.2018.11.035

26. Tomky D. Detection, prevention, and treatment of hypoglycemia in the hospital. Diabetes Spectr. 2005;18(1):39-44. doi:10.2337/ diaspect.18.1.39

27. Madani AM, Mahmoud AN, Abdelrahim HM, El-Hadiyah TM, Yousif AK. Assessing knowledge of hypoglycemia symptoms among type 2 diabetic patients using insulin, Khartoum, Sudan. Pharmacol Pharm. 2019;10(1):21. doi:10.4236/pp.2019.101003

28. Dailey G, Gao L, Aurand L, Garg S. Impact of diabetes duration on hypoglycaemia in patients with type 2 diabetes treated with insulin glargine or NPH insulin. Diabetes Obes Metab. 2013;15 (12):1085-1092. doi:10.1111/dom.12131

29. LaManna J, Litchman ML, Dickinson JK, et al. Diabetes education impact on hypoglycemia outcomes: a systematic review of evidence and gaps in the literature. Diabetes Educ. 2019;45(4):349-369. doi:10.1177/0145721719855931

30. Davis S, Alonso MD. Hypoglycemia as a barrier to glycemic control. $J$ Diabetes Complications. 2004;18(1):60-68. doi:10.1016/S10568727(03)00058-8 


\section{Publish your work in this journal}

Diabetes, Metabolic Syndrome and Obesity: Targets and Therapy is an international, peer-reviewed open-access journal committed to the rapid publication of the latest laboratory and clinical findings in the fields of diabetes, metabolic syndrome and obesity research. Original research, review, case reports, hypothesis formation, expert opinion and commentaries are all considered for publication. The manuscript management system is completely online and includes a very quick and fair peer-review system, which is all easy to use. Visit http://www.dovepress.com/testimonials.php to read real quotes from published authors.

Submit your manuscript here: https://www.dovepress.com/diabetes-metabolic-syndrome-and-obesity-targets-and-therapy-journal 